\title{
Emotion regulation in response to daily negative and positive events in youth: The role of event intensity and psychopathology
}

Anu P. Hiekkaranta ${ }^{1 *}$, Olivia J. Kirtley ${ }^{1}$, Ginette Lafit ${ }^{1,2}$, Jeroen Decoster ${ }^{3}$, Catherine Derom $^{4,5}$, Marc de Hert ${ }^{1,6,7}$, Sinan Gülöksüz ${ }^{8,9}$, Nele Jacobs ${ }^{8,10}$, Claudia Menne-Lothmann ${ }^{8}$, Bart P. F. Rutten ${ }^{8}$, Evert Thiery ${ }^{11}$, Jim van Os ${ }^{8,12,13}$, Ruud van Winkel ${ }^{1,6}$, Marieke Wichers ${ }^{14}$, \& Inez Myin-Germeys ${ }^{1}$

${ }^{1}$ KU Leuven, Department of Neurosciences, Research Group Psychiatry, Center for Contextual Psychiatry, Leuven, Belgium

${ }^{2}$ Department of Psychology, Research Group of Quantitative Psychology and Individual Differences, KU Leuven, Leuven, Belgium

${ }^{3}$ Sint-Kamillus, University Psychiatric Center, Bierbeek, Belgium

${ }^{4}$ Department of Obstetrics and Gynaecology, Ghent University Hospital, Ghent, Belgium

${ }^{5}$ KU Leuven, Department of Human Genetics, University Hospital Gasthuisberg, Leuven, Belgium

${ }^{6}$ University Psychiatric Centre KU Leuven, Department of Neurosciences, KU Leuven, Belgium

${ }^{7}$ Antwerp Health Law and Ethics Chair - AHLEC University Antwerpen, Antwerp, Belgium

${ }^{8}$ School for Mental Health and Neuroscience MHeNS, South Limburg Mental Health and Teaching Network, EURON, Department of Psychiatry and Neuropsychology, Maastricht University, The Netherlands

${ }^{9}$ Department of Psychiatry, Yale School of Medicine, New Haven, CT, United States

${ }^{10}$ Faculty of Psychology and Educational Sciences, Open University of the Netherlands, Heerlen, The Netherlands

${ }^{11}$ Department of Neurology, Ghent University Hospital, Ghent, Belgium

${ }^{12}$ Brain Center Rudolf Magnus, University Medical Centre Utrecht, Utrecht, The Netherlands

${ }^{13}$ Department of Psychosis Studies, Institute of Psychiatry, King's Health Partners, King's College London, London, $U K$

${ }^{14}$ University Medical Center Groningen, Department of Psychiatry, Interdisciplinary Center Psychopathology and Emotion Regulation, University of Groningen, Groningen, The Netherlands

*Corresponding author: Anu P. Hiekkaranta, Center for Contextual Psychiatry, KU Leuven, Department of Neurosciences, Kapucijnenvoer 7 bus 7001 (block H), 3000 Leuven, Belgium.

E-mail: anupauliina.hiekkaranta@kuleuven.be 


\section{Acknowledgments}

Anu Hiekkaranta and Inez Myin-Germeys are supported by an FWO Odysseus grant (Myin-Germeys, FWO GOF8416N), including a PhD studentship to Anu Hiekkaranta, Olivia Kirtley is supported by a Senior Postdoctoral Fellowship from Research Foundation Flanders (FWO 1257821N), and during preparation of this manuscript was also supported by a postdoctoral fellowship from an FWO Odysseus grant to Inez MyinGermeys (FWO GOF8416N). Ruud van Winkel is supported by an FWO Senior Clinical Fellowship (FWO 1803616N). Data used in the current study come from the TwinssCan study, which received funding from the European Community's Seventh Framework Program under grant agreement No. HEALTH-F2-2009-241909 (Project EU-GEI). Sinan Gülöksüz is supported by a ZonMw grant 636340001 from the Ophelia research project.

\section{Author contributions}

A. P. Hiekkaranta, O. J. Kirtley, and I. Myin-Germeys developed the concept for the current study. A. P. Hiekkaranta performed data analysis under the supervision of O. J. Kirtley, and with guidance from G. Lafit, and drafted the manuscript. G. Lafit conducted the power analysis and simulations. O. J. Kirtley and I. MyinGermeys provided critical revisions of the draft. J. Decoster, C. Derom, M. De Hert, S. Gülöksüz, N. Jacobs, C. Menne-Lothmann, B.P.F. Rutten, E. Thiery, J. van Os, M. Wichers, \& R. Van Winkel developed the overall study design for TwinssCan, and were involved in data collection. All authors approved the final version of the manuscript for submission.

Declarations of interest: none 


\begin{abstract}
Environmental and individual contextual factors profoundly influence how people regulate their emotions. The current article addresses the role of event intensity and psychopathology (an admixture of depression, anxiety, and psychoticism) on emotion regulation in response to naturally occurring events. For six days each evening, a youth sample (aged 15-25, $N=713$ ) recorded the intensity of the most positive and most negative event of the day and their subsequent emotion regulation. The intensity of negative events was positively associated with summed total emotion regulation effort, strategy diversity, engaging in rumination, situation modification, emotion expression, and sharing and negatively associated with reappraisal and acceptance. The intensity of positive events was positively associated with strategy diversity, savoring, emotion expression, and sharing. Higher psychopathology symptoms were only related to ruminating more about negative events. We interpret these findings as support for the role of context in the degree of effort and type of emotion regulation that young people engage in.
\end{abstract}

Keywords: emotion regulation, experience sampling method, adolescence, psychopathology, positive emotion regulation 


\section{Introduction}

From infancy to old age, the landscape of our daily emotional experiences is dynamic. A key process that plays a role in the fluctuation of emotions is emotion regulation; individuals' efforts to change the type, intensity, duration, or expression of the emotions they experience (Gross, 1998; 2015). Because regulating emotions allows individuals to influence "the dynamics of each emotion in order to produce adaptive responses to the environment" (Aldao, 2013, p. 155), emotion regulation is also a crucial element of mental wellbeing. Indeed, the transdiagnostic role of negative and positive emotion regulation is well documented in the maintenance and treatment of psychopathology in adults (Aldao, Nolen-Hoeksema, \& Schweizer, 2010; Berking et al., 2008; Carl, Soskin, Kerns, \& Barlow, 2013). Previous research, however, has paid less attention to how associations between emotion regulation and mental health differ over the course of the transition from adolescence to adulthood.

Adolescence has been described fittingly as the age of emotional "peaks and valleys" (Csikszentmihalyi \& Larson, 1984). Compared to adulthood, the daily lives of adolescents are characterized by more intense emotions (Larson, Csikszentmihalyi, \& Graef, 1980; Verma, \& Larson, 1999; Silk, Steinberg, \& Morris, 2003) and greater fluctuations in moods (Larson \& Richards, 1994). Moreover, during adolescence symptoms of most psychopathologies increase and it is therefore a critical phase in the development of the relationship between mental health and emotion regulation. Yet, only a few studies have investigated psychopathology and emotion regulation in young people in the context in which regulation naturally occurs: in the fabric of daily life, in response to personally relevant events.

\section{Investigating emotion regulation in daily life}

The development of daily life research has allowed researchers to begin investigating how several previously unexplored aspects of emotion regulation relate to psychopathology in adolescence and adulthood. As methods for investigating psychological and behavioral 
processes in daily life improved in recent years, the field of study concerning naturally occurring emotion regulation also began to take shape. Using methods like the Experience Sampling Method, a structured diary approach, where participants are prompted to respond to questionnaires about events, thoughts, moods, symptoms, behaviors, and other states in their daily lives (ESM; Csikszentmihalyi \& Larson, 1987; Myin-Germeys et al., 2018), has allowed emotion regulation researchers to collect more ecologically valid data in novel ways. These methods have also made it possible for researchers to begin the important work of investigating how mental well-being and other individual and contextual variables relate to emotion regulation outside the laboratory.

In the present investigation we focus on two elements of emotion regulation in daily life in response to emotional instances: emotion regulation effort (i.e. the degree to which specific strategies are employed) and the diversity of emotion regulation (i.e. the number of different strategies employed). We also draw on the literature on the use of emotion regulation strategies (i.e. whether a strategy is employed or not). Problems in each of these elements (use of individual strategies, effort per strategy, strategy diversity, total effort) could play a role in the difficulties with regulating positive and negative emotions that characterize many types of psychopathologies in adolescence (Compas et al., 2017).

\section{Psychopathology and emotion regulation in the wild}

Recent daily life research on emotion regulation supports the theoretical position that associations between emotion regulation and symptoms of mental disorders may strengthen from adolescence to adulthood (Compas et al., 2017), at least in the case of regulating negative emotions. While the literature is limited, existing daily diary studies in adolescent samples have not found an association between psychopathology and use of most of the commonly measured emotion regulation strategies. Tan et al. (2012) observed no differences between adolescents diagnosed with an anxiety disorder (generalized anxiety disorder, social anxiety disorder, or 
social phobia) and a control group, aged 9-13, in the use of six emotion regulation strategies (distraction, cognitive restructuring, problem solving, acceptance, avoidance, and rumination). Tan et al. (2012), however, found that anxious adolescents were less effective in downregulating negative emotions via acceptance and that rumination had a more detrimental effect on their subsequent emotions compared to non-anxious adolescents.

Likewise, Lennarz, Hollenstein, Lichtwarck-Aschoff, Kuntsche, and Granic (2019) found that in adolescents aged 12-17, use of emotion regulation strategies in daily life (avoidance, distraction, problem-solving, social support, reappraisal, rumination, acceptance, or suppression) was not associated with symptoms of depression, except that higher depression was associated with less acceptance for boys. However, Silk et al. (2003) found that adolescents (12-17-years old) who used disengagement strategies (e.g., denial), and involuntary engagement strategies (e.g., rumination) more often in response to negative emotions, reported more depressive symptoms.

Insights from adult studies suggests that it may not be the use of emotion regulations strategies that differs between those with and without psychopathology, but rather the degree of emotion regulation effort. Indeed, daily life studies of adults suggest that affective and psychotic psychopathologies are associated with greater effort in employing a variety of emotion regulation strategies. In a daily diary study of adults with and without schizophrenia, researchers assessed effort per emotion regulation strategy and the sum total of emotion regulation effort in response to daily events. People with schizophrenia reported using suppression, reappraisal, soothing, distraction, and avoidance more in response to negative events throughout the day compared to those without schizophrenia (Visser et al., 2015). Likewise, bipolar I disorder and major depression in adults have been associated with greater effort in using reappraisal, calming, suppression, and distraction for regulating daily negative emotions (Gruber, Kogan, Mennin, \& Murray, 2013). 
Few studies have explicitly investigated emotion regulation strategy diversity in daily life in relation to psychopathology. Research by Visser and colleagues (2015) found that adults with schizophrenia reported using a greater number of strategies per event in daily life, suggesting elevated emotion regulation effort in the form of using a large range of strategies. Similarly, a study where participants were asked to recall an emotional event found that adolescents who were the least likely to engage in a broad repertoire of emotion regulation strategies, - including reappraisal, acceptance, and problem-solving - in response to a recent emotional experience showed the lowest symptoms of anxiety, depression and borderline personality (Sloan et al., 2019). These studies contradict the existing (non-ESM) literature reporting a positive relationship between use of reappraisal and acceptance, and better mental health (Aldao et al., 2010). This suggests that not only is higher levels of psychopathology symptoms associated with employing a greater diversity of strategies in response to a single event, but that this repertoire includes the use of putatively adaptive strategies. Therefore, to understand what drives the apparently elevated emotion regulation effort and strategy use in psychopathology, and to examine whether the same patterns of effort and strategy use are present in adolescence, the inclusion of naturally occurring contextual factors in emotion regulation is critical.

\section{The role of emotion intensity in strategy use and diversity}

The role of key contextual factors, such as the intensity of daily emotional experiences, in emotion regulation across different psychopathologies, requires further investigation. Before interest in contextual factors in emotion regulation took off, a large body of results from laboratory experiments and self-report questionnaires converged on a positive relationship between 'active' strategies, such as problem solving and reappraisal, and better mental health. In contrast, 'passive' strategies such as rumination and avoidance have primarily been associated with higher psychopathology in non-daily life research (Aldao et al., 2010). Until 
recently, these findings were interpreted as evidence that emotion regulation strategies fall into 'adaptive' and 'maladaptive' categories based on the direction of their association with psychopathology (Aldao et al., 2010). However, studies of naturally occurring emotion regulation and its relationship with psychopathology do not reflect this divide (Visser et al., 2018; Gruber et al., 2013) and call into question the usefulness of categories such as 'adaptive' and 'maladaptive'. Meta-analytical evidence and a daily life investigation have shown that nonetheless, some strategies appear more likely to be used at the same time and that strategy co-occurrence differs within- and between people (Naragon-Gainey, McMahon, \& Chacko, 2017; McMahon \& Naragon-Gainey, 2019). These studies suggest that contextual variables, such as the intensity of emotional experiences, may be an important factor in when and to what degree different emotion regulation strategies are used.

Studies suggest that the intensity of negative emotions and events is associated with both the use of individual strategies as well as the use of a broader array of strategies. A selfreport questionnaire study in adults found that when participants were asked about their recollections of regulating negative emotions in response to moderately and highly intense situations, they reported using more strategies when events were highly intense (Dixon-Gordon, Aldao, \& De Los Reyes, 2015). Consistent with this, Lennarz et al. (2019) found in their daily life study of adolescents, that intensity of negative emotions was positively associated with the number of employed strategies. Additionally, the odds of employing avoidance, distraction, problem-solving, social support, rumination, and suppression all increased as reported emotional intensity increased (Lennarz et al., 2019).

If the use of emotion regulation strategies, strategy diversity, and effort are partially contingent on the intensity of emotional experiences, it may be that the previously documented difference in emotion regulation strategy use - measured with retrospective single time-point questionnaires - between those with and without symptoms of mental illness reflect, in part, 
differences in the intensity of daily negative experiences. Compared with control participants, adult patients with schizophrenia, depression, and bipolar disorder consistently report more intense negative affect in daily life (Visser et al., 2015; Gruber et al., 2013). Silk et al. (2003) also found that depressive symptoms were associated with experiencing greater daily negative affect in adolescence. Therefore, it is imperative to include emotional intensity or the intensity of emotion-eliciting events when investigating the role of psychopathology in daily life emotion regulation. Furthermore, to gain full insight into this relationship, it is crucial that regulation of positive emotions is not neglected; to our knowledge, no study has investigated the role of the intensity of positive events in the regulation of daily positive emotions.

\section{Positive emotions and psychopathology}

In general, few studies have investigated emotion regulation in the context of positive events or emotions in the daily lives of adolescents. In a daily diary study, Deng, Sang, \& Luan (2013) found that, based on qualitative data, healthy adolescents aged 12-18 engaged in several strategies to upregulate their emotions more often in response to positive affect compared to negative affect. Li, Starr, \& Hershenberg (2017) found in a study of young adults that daily rumination effort regarding positive events, also referred to as 'savoring', was negatively associated with daily depressive symptoms. In adults, Ma, Bryant, \& Hou (2020) also found that higher positive trait rumination was associated with greater positive affect during positive events. Furthermore, in adulthood, a dispositional tendency to think about one's positive experiences and allocate attention to them has been associated with higher life-satisfaction and lower depression (Bryant, 2003).

Research has also shown that in adulthood, telling others about positive events, also referred to as sharing, is common in daily life, with sharing occurring in response to the most positive event of the day $60-80 \%$ of the time (Gable, Reis, Impett, \& Asher, 2004; Gable \& Reis, 2010; Peters, Reis \& Gable, 2018). Social sharing of positive events has also been 
associated with increased well-being and life satisfaction (Peters et al, 2018). Further, Hershenberg, Davila, and Leong (2014) found that adult women with depression were less likely than control participants to share positive life events with others and showed a preference to sharing negative life events. However, compared to control participants, women with depression benefitted more from sharing positive life events, as indicated by an increase in positive mood and decrease in negative mood.

Efforts to increase and maintain positive emotions may be associated with better wellbeing and mental health in general. In a daily diary study, Blalock, Kashdan, \& Farmer (2016), assessed reappraisal effort to explicitly experience more positive emotions such as happiness in adult control participants and participants with social anxiety disorder (SAD). Those with SAD reported that they used less reappraisal to increase positive affect, compared to controls, suggesting decreased effort to upregulate positive affect. Similarly as with depression and sharing about positive events, compared to control participants, patients with SAD experienced more positive emotions on the days when they reported effort to upregulate their positive emotions. Moreover, Gruber and colleagues (2013) found in a daily diary study of patients with major depressive disorder, patients with bipolar I disorder, and control participants that both positive and negative emotionality were positively associated with reappraisal use at the momentary level. Additionally, Panaite, Devendorf, Kashdan, and Rottenberg (2021) reported that, remarkably, the number of positive events in daily life can have far-reaching consequences and even predicted well-being among adults with depression a decade later. Panaite and colleagues (2021) postulate that their finding could reflect how positive events are experienced and appraised, elements which emotion regulation is likely to influence. Moreover, as indicated by findings also outside the daily life field, using a variety of strategies to increase and maintain positive emotions appears positively associated with life 
satisfaction and happiness (Quoidbach, Berry, Hansenne, \& Mikolajczak, 2010; Gomez-Baya, Mendoza, Gaspar, \& Gomes, 2018).

Together existing research on emotion regulation in response to positive events suggests that upregulating positive emotions, by savouring, sharing, or using multiple strategies, is beneficial for mental well-being. This is consistent with the broaden-and-build model of positive emotions, which posits that cultivating positive emotions results in increased resilience (Fredrickson, 1998; 2001). However, at present little is known about how daily use of upregulation strategies and regulation effort in response to positive events is related to mental health or to the intensity of positive events in adolescence. One possibility is that, similar to the regulation of negative emotions in daily life, the use of positive emotion regulation strategies, the degree of effort, and strategy diversity could be influenced by the intensity of daily positive emotional experiences. Therefore, including the intensity of daily positive emotional experiences when investigating the role of psychopathology in regulating positive emotions, could bring further insight into the relationship between psychopathology and positive emotion regulation in adolescence.

\section{The current study}

In the current study, using a pre-existing ESM dataset, we investigated how psychopathology and event intensity were associated with emotion regulation in the context of daily life in a large population-based youth sample (aged 15-25). In order to represent the developmental stages of older adolescence and transition to adulthood, we conducted all analyses separately for the entire sample, older adolescents (aged 15-18), and adolescents in transition to adulthood (aged 19-22). The research questions, hypotheses, analysis plan, and code were post-registered (i.e., after data collection, but prior to access and analysis of the data; Benning, Bachrach, Smith, Freeman, \& Wright 2019) on the Open Science Framework. 
We initially planned to investigate symptoms of anxiety, depression, and psychoticism separately, however, a recent study in our lab using the same dataset found these subscale scores to be highly correlated (>.80; Achterhof et al., 2020). This is consistent with existing factor analytical findings suggesting the co-occurrence and unidimensionality of psychotic phenomena, depression, and anxiety in adolescence (Stochl et al., 2015). Therefore, anxiety, depression, and psychoticism were collapsed into a single measure of psychopathology. In order to represent different stages in the process of emotion regulation as outlined by Gross (1998; 2015) (situation selection, situation modification, attention deployment, cognitive change, and response modulation), we investigated strategies from each stage and therefore included avoidance, situation modification, rumination, reappraisal, expression, and sharing in response to negative events. For positive emotion regulation, three emotion regulation items were available in the dataset, all of which we considered emotion upregulation strategies and therefore appropriate for inclusion in this investigation: savoring, expression, and sharing in response to positive events.

Our hypotheses for the current study were as follows:

In response to the most negative event of the day during ESM:

1) Negative intensity of the event is associated with more emotion regulation effort in total, per strategy, and the employment of more strategies per event.

2) Higher (relative to lower) baseline psychopathology is associated with more emotion regulation effort in total, per strategy, and the employment of more strategies.

3) The interaction between psychopathology and intensity is significant, such that higher (relative to lower) psychopathology is associated with a stronger relationship between event intensity and total emotion regulation effort, the number of selected strategies, and effort per strategy. 
In response to the most positive event of the day during ESM:

4) Positive intensity of the event is associated with more emotion regulation effort per strategy and the employment of more strategies per event.

5) Higher (relative to lower) baseline psychopathology is associated with less emotion regulation effort per strategy and the employment of fewer strategies.

6) The interaction between psychopathology and intensity is significant, such that higher (relative to lower) psychopathology is associated with a weaker relationship between event intensity and the number of selected strategies and effort per strategy.

Hypothesis 3 was motivated by Visser et al. (2015), who found that schizophreniapatient status was associated with increased emotion regulation effort at also lower degrees of emotional intensity compared to controls. In a similar vein, to investigate if psychopathology symptoms were associated with a weaker relationship between intensity of positive events and positive emotion regulation, we also assessed the interaction effect between psychopathology symptoms and intensity on regulating positive emotions (Hypothesis 6).

For the most negative daily event during ESM, we also expected higher (relative to lower) baseline psychopathology symptoms would be associated with greater negative intensity. Finally, we expected that for the most positive daily event during ESM, higher (relative to lower) baseline psychopathology symptoms would associated with lower positive intensity.

After the post-registration (i.e., pre-analysis, post-data collection) of the current study, we noted a lack of literature investigating relationships between how people regulate their positive emotions and how they regulate their negative emotions. Daily life research is ideally suited for exploring the possibility of naturally occurring general emotion regulation styles across valence. Therefore, following post-registration, we explored the relationship between 
emotion regulation in response to positive events and emotion regulation in response to negative events.

\section{Methods}

\section{Participants}

The sample was collected as part of the TwinssCan study (Pries et al., 2019) a large longitudinal study conducted by KU Leuven and Maastricht University, within the European Network of National Schizophrenia Networks Studying Gene-Environment Interactions (EUGEI). Participants were recruited from the population-based twin registry, the East Flanders Prospective Twin Survey (EFPTS; Derom et al., 2019). Adolescents within the registry, aged 15-18, and their non-twin siblings, aged 15-34, were contacted to participate in the original TwinssCan study, resulting in a total sample of 790 participants. Twelve participants did not participate in the daily diary measures, and were excluded from the original dataset. For the purposes of the current study, we included participants aged $15-25$, in line with the definition of youth (Sawyer, Azzopardi, Wickremarathne, \& Patton, 2018). The final sample size of the current study was 713 (417 females). The TwinssCan study was approved by the local ethical committee (Commissie Medische Ethiek van de Universitaire ziekenhuizen KU Leuven, No. B32220107766). Participants older than 18 provided written consent. For participants younger than 18, parents and participants provided written consent.

\section{Measures}

\section{The Experience Sampling Method (ESM)}

The Experience Sampling Method is a structured daily diary method where data are collected by prompting participants to fill in a short questionnaire assessing states, thoughts, behaviors, mood, symptoms, or physical contexts several times throughout the day, over a period of time (Csikszentmihalyi \& Larson, 1987; Myin-Germeys et al., 2018). In the current 
study, participants were prompted to fill in an ESM questionnaire ten times a day for six consecutive days, and to fill in an evening questionnaire at the end of the day. Only the data from the evening questionnaire were used in the current study. After the prompt, participants had a 15-minute time window to respond to the questionnaire. The Psy-mate (C) (www.psymate.eu), a mobile phone-like Personal Digital Assistant (PDA), was used to prompt and deliver questionnaires and participants responded to the questionnaires on the device. Participants received training on how to fill in the ESM questionnaires. A research assistant practiced all the questions with the participants and participants had the opportunity to ask questions about the meaning of any specific items during the practice. Participants were paid a fixed amount of 25 euros for their participation in the ESM study. During the study, participants did not receive information on their compliance and they were paid the full amount regardless of their compliance.

\section{Psychopathology}

To assess psychopathology, the Dutch version of the Symptom Checklist-90-Revised (SCL-90-R; Derogatis et al., 1979) was used. The SCL-90-R was included in the original battery of baseline questionnaires within the TwinssCan study. The SCL-90-R is a self-report questionnaire used to measure the intensity of a variety of psychological symptoms, where participants are asked to reflect on how bothered they have been by different symptoms in the past week. In the current study, we used the subscales for depression (13 items, e.g., "Feeling hopeless about the future"), anxiety (10 items, e.g., "Worrying too much about things"), paranoid ideation (6 items, e.g., "Feeling that you are watched or talked about by others"), and psychoticism (10 items, e.g., "Having thoughts that are not your own"). Participants responded to all items on a 0 to 4 scale ( $0=$ "Not at all", 4 = "Extremely"). Psychoticism, paranoid ideation, depression, and anxiety subscales were combined into a single dimension of psychopathology by summing up all the scores on items from all four subscales, resulting in a possible 
psychopathology range of $0-156$. The MacDonald's Omega for the single dimension psychopathology measure in the current sample was 0.96 .

\section{Emotion regulation}

Emotion regulation in response to the most negative event of the day was assessed at the end of the day with the ESM item: "Think about the most NEGATIVE event of the day". This item was followed by seven emotion regulation items: "I talked about it with somebody" (social sharing; 1 = "Yes", $0=$ "No"), "I have thought about it a lot" (rumination), "I reappraised it" (reappraisal), "I just let it happen" (acceptance), "I expressed my emotions" (expression), "I tried to forget about it quickly" (avoidance), "I tried to change the situation" (situation modification) $(1-7,1=$ "Not", 7 = "Very much"). The sum of responses to all the emotion regulation items represented total emotion regulation per daily most negative event. Social sharing was excluded from the total emotion regulation score because its scoring was binary. The number of strategies per event was calculated as the total of strategies where participants responded with a 2 or higher, or "yes" in the case of social sharing. Participants also indicated their experience of the emotional intensity of the event: "This event was" $(-3=$ "Very unpleasant", $-2,-1,0,+1,+2,+3=$ "Very pleasant"). In order to exclude counterintuitive responses and responses where the most negative event of the day was a positive event, responses to the emotional intensity item were excluded if they were 1 or higher.

Emotion regulation in response to the most positive event of the day was assessed at the end of the day with the ESM item: "Think about the most POSITIVE event of the day". This item was followed by three emotion regulation items: "I talked about it with somebody" (social sharing), "I have thought about it a lot" (savoring), "I expressed my emotions" (expression) (1 $=$ "Not, $7=$ "Very much"). Only these three positive emotion regulation strategies were included in the original dataset, and therefore we did not calculate a total emotion regulation score. The same procedure as with negative events for calculating the strategies per event-score 
was used for positive events. Participants also indicated their experience of the emotional intensity of the event: "This event was" (-3 = "Very unpleasant", $-2,-1,0,+1,+2,+3=$ "Very pleasant"). In order to exclude counterintuitive responses and responses where the most positive event of the day was a negative event, responses to the emotional intensity item were excluded if they were -1 or lower. All ESM items were administered in Dutch.

Data used in the current study were pre-existing, and were collected by a different research team. Unfortunately, no information on the development of the emotion regulation items was available from the dataset curators. Notably, however, at present no validated ESM emotion regulation items are available for general use (Mestdagh \& Dejonckheere, 2021). To address this and other ESM-related measurement issues, we are currently also developing the ESM Item Repository to share and facilitate validation of emotion regulation items (Kirtley et al., 2019).

\section{Statistical Analyses}

All hypotheses were tested with multilevel regressions with random slopes (as in e.g., Vaessen et al., 2017) using R software (R Core Team, 2019), R studio version 3.6.0 (RStudio Team, 2015) and the lme4 (Bates, Maechler, Bolker, \& Walker, 2015) and lmerTest (Kuznetsova, Brockhoff, \& Christensen, 2017) packages. We compared the suitability of two models for the data structure for each multilevel mixed regression: a 3-level model (Model 1) and a 2-level model (Model 2). Model 1 included days (ESM) nested in persons and persons were nested in twins. Model 2 included days (ESM) nested in persons. We generated 100 bootstrapped samples from the dataset and tested both models on all bootstrapped samples. Each sample was $1 / 3$ and $2 / 3$ of the total sample $(N=713)$. Model 2 had few samples that showed convergence problems per mixed regression, while Model 1 had convergence problems with most mixed regressions. (Appendix A). Therefore, we conducted the analyses using Model 2 (see Appendix A for details). 
To assess the relationship between the intensity of the most negative event of the day and psychopathology with emotion regulation outcomes, separate mixed multilevel regressions were conducted with total emotion regulation, number of selected strategies, rumination, acceptance, expression, social sharing, reappraisal, situation modification, and avoidance as outcomes. We also included age and gender as covariates, and the interaction between negative event intensity and psychopathology in the analyses. We conducted the same analyses on the relationship between daily most positive event intensity and psychopathology with emotion regulation outcomes: number of selected strategies, savoring, expression, and sharing. In analyses regarding daily most positive events, we also included the covariates age, gender, and the interaction between event intensity and psychopathology. To assess the relationship between daily most positive and negative event intensity and psychopathology, an additional two mixed multilevel regressions were conducted, also with age and gender as covariates.

Finally, we explored the relationship between emotion regulation in response to positive events and emotion regulation in response to negative events. This exploration involved mixed multilevel regressions with the same data structure (Model 2) where each emotion regulation outcome per negative event was regressed on each parallel emotion regulation outcome per positive event, including age and gender as covariates. Thus, we explored if ruminating about the most negative event of the day was associated with savoring the most positive event of the day, if expressing emotions in response to positive events was associated with expressing emotions about negative events, and if talking about positive events was associated with talking about negative events.

Because analyses regarding per strategy outcomes were conducted separately and involved multiple significance tests, we applied the conservative Bonferroni correction. For analyses regarding daily most negative event, this resulted in a significance level of $0.05 / 7=$ 0.007 , and $0.05 / 3=0.016$ for analyses regarding daily most positive event. This was a 
deviation from the originally planned less conservative Holm-Bonferroni method of correction, as stated in the post-registration of these analyses. This decision was motivated by the observation that the majority of significant results presented in the current study were coupled with very small p-values and there was therefore less concern of type II error than we expected. For that reason, the more conservative Bonferroni method was considered appropriate. To avoid obtaining biased estimates with the number of observations per persons being fewer than 10 , within-person analyses were not considered appropriate and were therefore not conducted (Hox, 2010; Ali et al. 2019).

\section{Data preparation}

The dataset containing all variables of interest was a subset of the complete TwinssCan dataset. This subset was accessed after the post-registration of hypotheses and analyses, and access was timestamped. Post-registration refers to "pre" registering analyses where large archival datasets collected over several years are used for new investigations (Benning et al., 2019). The post-registration (https://osf.io/k8pre/?view_only=ac582a5408a84a78aced18d6dda83add) and the code for data analysis and power calculation (https://osf.io/jepyb/?view_only=15e0735b06a04d45889d9ce3dc6dc7c3) are both available on the Open Science Framework.

The subset dataset consisted of 790 participants. In preparation for analyses, all rows containing missing participant ID's were removed, resulting in 789 participants. Rows containing missing information on day number were removed, with 778 participants remaining. Because the dataset had been cleaned prior to the current study, there was only one participant who had responded to less than $30 \%$ of the ESM evening questionnaires and this participant was removed. Removing instances where daily most negative event was rated as pleasant ( 1 or higher on a -3 to +3 scale, -3 = "Very unpleasant", +3 = "Very pleasant") resulted in 753 
participants remaining. Removing instances where daily most positive event was rated as unpleasant (-1 or lower on a -3 to +3 scale, $-3=$ "Very unpleasant", $+3=$ "Very pleasant") resulted in 750 participants remaining. In these cases, participants were only removed if they reported all negative events as positive or all positive events as negative, otherwise, only specific instances were removed. Finally, participants older than 25 were removed, resulting in a final sample of 713 . The ESM compliance rate of the final sample was $73 \%$, meaning that participants had completed the daily diary on 4.4 days on average. Finally, in the current study variables were not centered, as recommended by Kelley, Evans, Lowman, and Lykes (2017). This was to avoid adding additional random error into the variables, as random measurement error may lead to substantially biased coefficient estimates in multilevel analyses (Kelley et al., 2017).

\section{Power analysis}

Because formal guidelines for procedures to estimate power for mixed multilevel analyses have not yet been provided, we piloted a power analysis procedure for these types of models as a part of the current study. We performed a Monte Carlo simulation (Arend \& Schäfer, 2019; Bolger, Stadler, \& Laurenceau, 2012) to test the following model:

$$
Y_{t i}=\beta_{00}+\beta_{01} Z_{i}+\beta_{10} X_{t i}+\beta_{11} Z_{i} X_{t i}+v_{0 i}+v_{1 t i} X_{t i}+\varepsilon_{t i}
$$

Where $Y_{t i}$ is the time-varying level 1 outcome variable (e.g. rumination) at time $t$ for individual $i . Z_{i}$ is a time-invariant level-2 variable (psychopathology) and $X_{t i}$ is a time-varying level-1 variable (intensity) at time $t$ for individual $i$. The random effects $v_{0 i}$ and $v_{l i j}$ capture the individual differences in $Y_{t i}$ around the mean levels of the independent variables. The errors $\varepsilon_{t i}$ capture specific variations around the individual mean. The grand mean is represented by $\beta_{00}$. Further, $\beta_{01}$ represents the effect of $Z_{i}, \beta_{10}$ represents the effect of $X_{t i}$ and $\beta_{11}$ the interaction effect. 
We generated 1000 Monte Carlo samples of the model and estimated the model for each simulated dataset. Using these 1000 fitted models, we tested the null hypothesis of the model for a significant level of the type I error alpha $=0.05$, for each parameter. We then summed up the number of times the effect was significant. The number of samples in which the null hypothesis was rejected given the sample size $N$ represented the power for detecting the effect. In order to estimate effects, we generated 100 bootstrapped samples of size $1 / 3$ of the total dataset. We then estimated the model with age and gender as covariates. Using the 100 bootstrapped samples, we calculated the mean of each parameter (i.e., effect) of interest. Based on these parameters, the power to estimate the effect of intensity on emotion regulation outcomes was $0.84-1.00$ for all outcomes except avoidance. The unstandardized effect size estimates ranged from 0.09 to 0.81 . The power to estimate the effect of psychopathology on emotion regulation outcomes ranged from 0.06 to 1.00 . The unstandardized effect sizes of psychopathology, with a range of 0.001-0.016 in magnitude, were considerably smaller compared to the effects of intensity, as the scale of the psychopathology variable was larger (see Appendix A for a full overview of parameter estimates and power per outcome and independent variable). In sum, the power to detect the effect of intensity on most emotion regulation outcomes was high. Conversely, the power to detect the effect of psychopathology on emotion regulation outcomes varied more and was mostly low (Appendix A). However, in analyses regarding daily most negative event, the power to detect the association between psychopathology and rumination was 1.00 and the power to detect the association between psychopathology and social sharing was 0.74 .

\section{Results}

\section{Descriptive statistics}

Descriptive statistics and frequency statistics for use of each emotion regulation strategy are shown in Table $1(N=713)$. Four participants aged younger than $15(14.22-14.91)$ were 
also included in the analyses. The analyses were conducted with and without these four participants and the exclusion of these participants did not affect the significance or direction of effects. For analyses, the psychopathology variable was scaled to range from $0-4$ to have a similar range as the intensity variable.

As seen in Table 1, in response to the most negative event of the day, acceptance was the most often used strategy, whereas savoring was the most used strategy for positive events. Positive strategies were used more often than their negative counterparts. In response to daily most negative event, in most instances more than one strategy was used. In $0.5 \%$ of negative events, no strategy was used. Across all negative events, one strategy was used in $1.9 \%$ events, two were used in $4.6 \%$ of events, three were used in $8.5 \%$ of events, four were used in $14.4 \%$ of events, five were used in $20.7 \%$ of events, six were used in $26.3 \%$ of events, and seven were used in $23.1 \%$ of events. Therefore, in $70 \%$ of the instances, five or more strategies were used. In response to daily most positive event, the same pattern was observed. In $5.9 \%$ of events, no strategy was used, with the use of only one strategy being rare, $13.0 \%$, and with two strategies being used in $31.2 \%$ of events, and three strategies used in $49.3 \%$ of events.

\section{The most negative event of the day}

\section{Total emotion regulation effort}

Presented in Table 2, intensity (i.e., how unpleasant the event was rated) was significantly associated with total emotion regulation effort, such that more unpleasant events were associated with more total effort to regulate emotions. Psychopathology was not associated with total emotion regulation effort. Likewise, the interaction between psychopathology and intensity was not significant. The covariate age was not associated with total effort, while the covariate gender was significantly associated with total effort such that females reported more emotion regulation effort in response to daily most negative events. 


\section{Strategy diversity}

As with total effort, intensity was significantly associated with the number of selected strategies, such that more intense events were associated with the employment of more strategies (Table 2). In response to the most negative event of the day, psychopathology was not associated with the number of employed strategies. The interaction between psychopathology and intensity was not significant. The covariate age was significantly positively associated with the number of employed strategies. Being female was significantly associated with the employment of more strategies per daily most negative event.

\section{Specific strategies}

Higher negative intensity was significantly associated with more rumination, situation modification, and expression, such that as events were rated as more unpleasant, more effort within these strategies was employed. Higher negative intensity was also associated with higher odds of engaging in sharing, such that a unit of increase in negative intensity was associated with a 1.55 higher odds of sharing. Lower intensity was associated with more acceptance and more reappraisal. Psychopathology was also not significantly associated with the employment of any specific strategy in response to daily most negative event, with the exception of a significant positive association with rumination and a close-to-significant negative association with sharing (Table 2). Psychopathology was associated with sharing such that a one unit increase in psychopathology (scaled to the range 0-4) was associated with a 1.72 times lower odds of talking to someone about the most negative event of the day, however, this association was not significant when the Bonferroni correction was applied $(p<0.014)$. The interaction between psychopathology and intensity was not significant. The covariate age was associated with using reappraisal significantly more. Finally, being female was significantly associated with ruminating and expressing emotions more, and with using acceptance less. 


\section{Psychopathology and negative intensity}

The intensity of the most negative event of the day was significantly associated with psychopathology, such that higher psychopathology was associated with rating the most negative event of the day as more unpleasant (Table 4). Covariates age and gender were not significantly associated with the intensity of daily most negative events.

\section{The most positive event of the day}

\section{Strategy diversity}

In response to the most positive event of the day, intensity of the positive event (i.e., how pleasant the event was rated as) was significantly associated with the employment of more strategies per event (Table 3). Psychopathology was not associated with the number of employed strategies. The interaction between psychopathology and intensity was not significant, in line with the results regarding daily most negative events. The covariate age was significantly positively associated with the number of selected strategies, and being female was associated with the employment of more strategies.

\section{Specific strategies}

Consistent with results regarding daily most negative event, in response to the most positive daily event, intensity was significantly associated with more use of all strategies, such that higher positive intensity was associated with more savoring, expression, and sharing (Table 3). Higher positive intensity was associated with sharing such that per unit of increase in positive intensity, the odds of sharing were 1.90 times higher. Psychopathology was not associated with the use of any specific strategy and the interaction between psychopathology and intensity was not significant. Age was positively associated with savoring related to daily most positive events. Being female was associated with more savoring of and expression of emotions in response to the most positive daily events. 


\section{Psychopathology and positive intensity}

The intensity of the most positive event of the day was not significantly associated with psychopathology (Table 4). Age was not significantly associated with positive intensity; however being female was associated with reporting the most positive daily event as significantly more pleasant.

\section{Exploratory analyses}

We explored if negative rumination was associated with positive savoring, if expressing emotions in response to negative events was associated with expressing emotions in response to positive events, and if talking to others about negative events (sharing) was associated with talking about positive events with others (Table 4). We found that ruminating about negative events was significantly associated with savoring positive events. Likewise, we found that expression of emotions in response to negative events was associated with more expression in response to positive events and that sharing about negative events was associated with sharing about positive events (Table 4). We controlled for the effect of age and gender.

Across confirmatory analyses, intensity was consistently significantly associated with emotion regulation outcomes. There was also a consistent lack of significant associations between psychopathology and negative emotion regulation across our analyses, apart from associations with rumination and sharing outcomes, despite a large existing literature supporting the relationship between a variety of emotion regulation strategies and psychopathology. Based on this, we explored the results after removing intensity from the models with emotion regulation outcomes and leaving psychopathology in the models. With the removal of intensity, psychopathology was significantly associated with more emotion regulation outcomes, such that in response to daily most negative events, psychopathology was positively associated with total emotion regulation effort $(\beta=0.97, \mathrm{SE}=0.01, p<0.01)$, 
rumination, $(\beta=0.89, \mathrm{SE}=0.10, p<0.001)$, situation modification $(\beta=0.27, \mathrm{SE}=0.11, p$ $<0.05)$, and negatively associated with reappraisal $(\beta=-0.39), \mathrm{SE}=0.11, p<0.001)$. With the removal of intensity from the models on emotion regulation outcomes regarding daily most positive event, psychopathology was significantly negatively associated with positive savoring $(\beta=-0.31, \mathrm{SE}=0.14, p<0.05$.

At the suggestion of a reviewer, we also conducted all confirmatory analyses on the total group again by replacing the composite psychopathology measure with the anxiety, depression and psychoticism subscales separately. We did not observe notable difference in the direction or magnitude of effects in general. However, we observed that anxiety was negatively associated with acceptance $(\beta=-0.18, \mathrm{SE}=0.08, p=0.026)$ while intensity was controlled for and intensity was still significantly negatively associated with acceptance as well $(\beta=-0.44$, $\mathrm{SE}=0.06, p<0.001)$. The results of these additional exploratory analyses are reported in Appendix C.

\section{Sensitivity Analyses}

Because the sample included a broad age range, the total sample was divided into age groups: older adolescents aged 15-18 $(N=582)$, adolescents transitioning to adulthood aged $19-22(N=115)$ and young adults aged 23-25 $(N=16)$. This was a deviation from the sensitivity analysis outlined in the post-registration of this study (comparison between age groups 15-20 and 21-25). The deviation was motivated by community feedback, in order to better represent the distinction between older adolescence and the transitional period between adolescence and adulthood. Because the young adults group $(N=22-25)$ was too small to be sufficiently statistically powered, we conducted all analyses separately for the older adolescent group (aged 15-18) and the transitional group (aged 19-22). The direction and strength of the associations for the confirmatory analyses in the older adolescent group did not differ considerably from the total sample (Appendix B). However, some notable differences were observed for confirmatory 
analyses in the transitional age group. For negative events, the relationship between event intensity and sharing was no longer significant, $(\beta=-0.08, \mathrm{SE}=0.19, p=0.65)$, while we observed an interaction effect of psychopathology and event intensity on sharing $(\beta=-0.76$, SE $=0.31, p=0.016)$. As event intensity was reverse-coded, the interaction indicates that with increasing psychopathology, the relationship between event intensity and sharing also increased in the group aged 19-22.

For positive events, the transitional group also differed from the total sample in the relationship between intensity of positive events and psychopathology. While in the total sample, psychopathology was not associated with the intensity of positive events, in the transitional group higher psychopathology was associated with experiencing positive events as less pleasant $(\beta=-0.26, \mathrm{SE}=0.11, p=0.017)$. Important to note, however, is that with the application of the Bonferroni correction ( $p<0.007$ as significant), these differences should be interpreted cautiously. All results from sensitivity analyses can be seen in Appendix B.

\section{Outliers}

Following post-registration, when conducting analyses we became aware that the range of the psychopathology variable was large, with an average score of 18.6 and a range of $0-149$. Therefore, all confirmatory analyses were also conducted without outliers on the psychopathology variable ( \pm 3 standard deviations from the mean). This resulted in the removal of 14 participants, all in the +3 standard deviations bound. The removal of these outliers affected two results of confirmatory analyses: higher psychopathology was associated with a larger number of emotion regulation strategies employed in response to the most negative event of the day $(\beta=0.22, \mathrm{SE}=0.09, p=0.015)$, and higher psychopathology was negatively associated with sharing in response to the most positive event of the day $(\beta=-0.33, \mathrm{SE}=0.13$, $p=0.012$ ). These models also included intensity as a predictor. Psychopathology was associated with sharing about positive events such that a one standard deviation increase in 
psychopathology was associated with a 1.28 lower odds of engaging in sharing about positive events.

\section{Discussion}

We investigated the role of psychopathology and event intensity, on daily emotion regulation in a large youth sample. The intensity of the most negative event of the day was positively associated with total emotion regulation effort, number of strategies, rumination, situation modification, expression, and sharing, supporting hypothesis 1. Contrary to hypothesis 1, intensity of negative events was negatively associated with acceptance and reappraisal. Higher psychopathology was only significantly associated with ruminating more about the most negative event of the day, and therefore hypothesis 2 was partially supported. We did not observe a significant interaction effect between psychopathology and intensity of negative events and emotion regulation outcomes in adolescents aged 15-18. However, we found that the relationship between intensity of negative events and sharing increased with higher psychopathology in adolescents in transition to adulthood (aged 19-22) and thus hypothesis 3 was partially supported. We also observed that higher psychopathology was positively associated with experiencing daily negative events as more intense, as hypothesized.

The intensity of the most positive event of the day was associated with more emotion regulation effort per strategy and the employment of more strategies per event, supporting hypothesis 4. In response to positive events, higher (relative to lower) psychopathology was not associated with emotion regulation effort per strategy or the employment of strategies, contradicting hypothesis 5 . Further, regarding positive events, we did not observe a significant interaction between psychopathology and intensity on emotion regulation outcomes (hypothesis 6). Finally, psychopathology was not associated with the intensity of the most positive event of the day for 15-18-year olds, contradictory to the hypothesis. As hypothesized however, in the 
group of adolescents in transition to adulthood, higher psychopathology was associated with experiencing the most positive event of the day as less positive.

Overall, we observed consistently significant relationships of intensity of both positive and negative events with emotion regulation outcomes. In contrast, when we accounted for event intensity, higher psychopathology was only related to ruminating more about negative events, and slightly lower odds of discussing negative events with others. Polyregulation, the use of multiple strategies in response to one event, stimuli, or emotion (Ford, Gross, \& Gruber, 2019), was likewise observed in response to positive and negative events and found to be positively associated with event intensity. Moreover, exploratory analyses showed positive covariances between daily emotion regulation responses across positive and negative events. Finally, we explored associations of age and gender with emotion regulation. In general, females regulated emotions more, and there appeared to be a positive relationship between age and positive savoring, positive expression, the number of strategies employed per positive and negative events, as well as age and reappraisal in response to negative events.

\section{Event intensity and daily regulation of negative emotions}

Intensity of the most negative event of the day was positively associated with the majority of emotion regulation outcomes, as hypothesized. In contrast to our hypotheses, acceptance and reappraisal were used more when intensity was lower, suggesting that these two strategies are exceptions to the rule that greater intensity of negative events is associated with more emotion regulation effort. In a sample of younger adolescents, Lennarz et al. (2019) found that the odds of engaging in acceptance in daily life increased as reported negative emotional intensity decreased, but did not find reappraisal to be significantly associated with intensity. Two possible explanations may account for the difference in findings on the relationship between reappraisal and intensity. First, it may be that adaptive use of reappraisal at lower emotional intensities is a skill that develops over time and is therefore more prevalent in older 
adolescence. Second, the power to detect the effect in the present study was high and likely higher than in the smaller sample in Lennarz et al's (2019) study. In contrast, current findings on reappraisal do echo those by Sheppes et al. (2011) and Sheppes et al. (2014). In their laboratory experiments, adult participants were presented with high- and low intensity negative images and asked to select if they wanted to regulate their emotions via distraction or reappraisal. Consistent with our findings, reappraisal was employed more when intensity was lower, suggesting that reappraisal is indeed adaptive when used in low intensity situations and that this effect can be observed in the controlled laboratory setting (Sheppes et al., 2011; Sheppes et al., 2014) and in daily life.

In the current study, negative event intensity was not associated with avoidance, in contrast with the findings of Lennarz et al. (2019), where greater negative intensity was associated with higher odds of engaging in avoidance. This discrepancy likely reflects important differences in ESM items. In the current study, avoidance was assessed with the item "I tried to forget about it quickly", while Lennarz et al. (2019) used the item "I avoided the situation where the event occurred". It could be that the item used in the current study captured both a lack of motivation to regulate when negative events were less intense, and the active cognitive effort to regulate when events were more intense. This issue is a part of broader concern with the lack of validated items in ESM research, as well as the absence of established psychometric criteria for ESM items (Wright \& Zimmermann, 2019). In particular, this matter is extremely relevant for psychological phenomena such as emotion regulation strategies, which are typically only assessed with a single item in ESM research.

\section{Event intensity and the daily regulation of positive emotions in youth}

In the current study, we found that in response to the most positive event of the day, intensity of the event was positively associated with engaging in more emotional expression, sharing, and savoring. This finding implies that adaptive emotion regulation includes 
responding to positive events with upregulation and maintenance of the positive affect state. To our knowledge, this is the first study to investigate the relationship between intensity of positive events and emotion regulation responses to positive events in daily life. Future studies may extend on these findings by investigating the relationship between stimuli intensity and a greater range of positive emotion regulation strategies as well as a range of discrete positive emotions.

\section{Polyregulation of emotions in daily life}

Overall, the present results suggest that, consistent with Dixon-Gordon et al. (2015) and Lennarz et al. (2019), greater intensity of daily negative events is associated with more total effort in regulating emotions, as well as the employment of more strategies in youth. In a recent review, the term polyregulation was introduced to describe instances where people engage in the use of multiple emotion regulation strategies simultaneously, or over time, in response to an emotion, emotional event or an emotional stimulus (Ford et al., 2019). The current results add important insight regarding polyregulation in daily life. In this study, five or more strategies were used in most instances of regulating emotions in response to a negative event. As participants reported on the use of different strategies at the end of the day in response to an event that occurred at some point during the day, the findings may reflect the use of several strategies simultaneously or over the course of the day. This finding is in line with Heiy and Cheavens (2014), who also found that on average, adults used seven strategies to regulate their negative emotions in response to a single event in daily life. Research from the coping literature that used retrospective measures has also shown that people indeed report using more than one strategy in almost all (98\%) instances of coping (Folkman \& Lazarus, 1980). The current findings also add to those of Lennarz et al. (2019), who found that when sampled over a short time frame of 90 minutes, adolescents used (on average) 1.2 strategies when regulating negative event-related emotions and in most instances ( $87 \%$ of the time) used only one strategy. Together these findings suggest that in youth, within 1-2 hours of a negative event, one emotion 
regulation strategy is likely to be employed, but as the day continues, several more strategies are likely to be implemented as well.

The differences in the number of employed strategies per event observed in different age groups may also reflect the maturation of emotion regulation, such that over time, emotion regulation repertoire grows and the degree of polyregulation increases. Indeed, our results support this account, as age was associated with the use of more strategies in response to negative events. In the current study, it is also possible that participants' emotions regarding the event changed over the course of the day and that different strategies may have been employed in response to different emotions. A more fine grained investigation of the course of emotion regulation in response to a single event and corresponding emotions over time is necessary to explore this possibility. Moreover, the list of strategies included in the current study is a selection from a larger possible repertoire of strategies. Therefore, it may be that the degree of event-related polyregulation observed in the current study is also an underestimation. Thus, future studies of daily emotion regulation in youth will benefit from the inclusion of as many strategies as feasible with the experience sampling method.

Our findings on polyregulation in response to single positive events align with those of Heiy and Cheavens (2014), who found that adults engaged in multiple emotion regulation strategies per positive event. While in the current study only three emotion regulation strategies in response to positive events were included, these results suggest that young people respond to positive events with a number of different emotion upregulation and maintenance strategies and that the degree of polyregulation is positively associated with intensity of positive events.

Finally, the current results suggest polyregulation is the normative response to both daily positive and negative events in youth. In the current study polyregulation may have occurred as the simultaneous employment of several strategies at once, overlapping employment, or discrete employment over time. This also implies that because polyregulation is likely more 
chaotic and instinctive than strategic, as suggested by Ford et al. (2019), most instances of emotion regulation in youth may occur with little deliberation and strategizing. Therefore, the term 'emotion regulation response' may indeed describe the regulation that young people engage in better than the term 'emotion regulation strategy'.

\section{Momentary and stable relationships between psychopathology and emotion regulation}

When we controlled for event intensity, higher psychopathology was only associated with ruminating about the most negative event of the day more, and with talking to someone about the most negative event of the day less (i.e., sharing), and the latter effect was not significant after a Bonferroni correction was applied. This finding is surprising, given that a large body of existing literature based on dispositional questionnaires has found psychopathology to also be associated with other strategies assessed in the current study, such as situation modification, acceptance, and reappraisal (Aldao et al., 2010). The findings thus highlight the importance of including event intensity in investigations of the role of psychopathology in daily emotion regulation. The current results also suggest that psychopathology may be associated with rumination in daily life through two different pathways. First, it appears that in youth, for those with higher psychopathology, rumination occurs regardless of event intensity, while for those with lower psychopathology ruminating more in response to more intense events may reflect an adaptive contingency of allocating attention to relevant events. Second, we found that higher psychopathology was associated with reporting the most negative event of the day as more unpleasant. This suggests that the positive association between psychopathology and rumination is also partly explained by heightened experience of intensity of negative events. Moreover, the negative associations observed in previous studies between psychopathology and other emotion regulations strategies previously labelled as adaptive, such as acceptance and reappraisal (Aldao et al., 2010), may also reflect heightened experience of intensity of negative events in daily life, rather the lack of effort in 
engaging in acceptance or reappraisal. Of note, is that it is not possible to draw inferences about whether or not participants with higher psychopathology actually experienced objectively more intense negative events in their daily lives or if they experienced the same events more intensely than those with lower psychopathology. However, psychotic and affective disorders have been associated with experiencing minor daily hassles as more intense, a sensitivity that may also increase the risk of developing psychopathology (Myin-Germeys et al., 2003; Vaessen et al., 2017). Therefore, it appears less likely that participants in the current study experienced objectively more unpleasant events and rather, that they reported heightened emotional reactions to minor negative daily events.

Psychopathology in youth was not associated with the number of emotion regulations strategies employed per positive event, with savoring positive events, with talking about them with others, or with emotional expression. This finding suggest that the psychopathology admixture assessed in the current study (i.e., anxiety, depression, and psychotic symptoms) does not compromise daily upregulation and maintenance of positive emotions in youth. Psychopathology was also not associated with reported intensity of the most positive event of the day for 15-18-year olds, suggesting that in older adolescence, positive daily experiences are not substantively affected by psychopathology. This implies that positive experiences provide a possible source of resilience for older adolescents and daily life mental health interventions could benefit from utilizing naturally occurring positive experiences. For adolescents in transition to adulthood, however, higher psychopathology was associated with reporting slightly less intense daily positive events. This discrepancy suggest that an intervention utilizing positive experiences may be easier to implement for 15-18-year olds, but that 19-22-year olds could benefit from it more.

We did not find significant interactions between psychopathology and negative intensity on any of the emotion regulation outcomes in the group of older adolescents (aged 15-19). It 
may be that in older adolescence, psychopathology as measured in the current study, is not associated with a lower intensity threshold of engaging in the regulation of negative emotions. Alternatively, it is possible that mild psychopathology is not associated with this type of issue in emotion regulation, but that rather a transition to more debilitating psychopathology in adulthood could be associated with the development of a hypersensitive emotion regulation response to negative emotions. However, in the group we considered as in transition to adulthood, aged 19-22, a sensitivity analysis suggested that the relationship between intensity of negative events and talking about them with others (sharing) increased with higher psychopathology. This result was not significant when the Bonferroni correction was applied, but is nonetheless a notable deviation from other main effects between event intensity and emotion regulation. The finding could reflect the development of adaptive emotion regulation, as with increasing age, people may be more likely to seek support from others in times of greater need. It may be that this window of adaptive behavior, or the availability of social support, is temporary, as adults with higher psychopathology such as schizophrenia, no longer exhibit a more sensitive threshold to seeking social support, while they do exhibit a more sensitive threshold to engaging in intrapersonal emotion regulation (Visser et al., 2018).

\section{Gender differences}

Gender was included as a covariate in the current study and we did not have specific hypotheses relating to this variable, therefore these findings are exploratory. In response to the most negative event of the day, girls ruminated more, expressed their emotions more, and shared more by talking with others, regulated emotion more in total, and with more strategies. These results support the tend-and-befriend model of stress responses in females (Taylor et al., 2000); expression of emotions and sharing may facilitate the development and maintenance of social networks. Girls also reported more emotional expression, in line with previous research (Fischer \& LaFrance, 2015), and sharing in response to positive events, further supporting in 
particular the befriending aspect of the tend-and-befriend model. Boys were more likely to report acceptance in response to negative events. There were no gender differences in the use of situation modification or avoidance in response to negative events. Lennarz et al. (2019) also found that girls used all strategies except acceptance more often than boys did. Differences in emotion regulation were not explained by differences in experienced emotional intensity. Previous research using dispositional measures has demonstrated that girls begin to ruminate more, report more stress, and experience higher symptoms of depression in early adolescence (Jose \& Brown, 2008). However, we also found that in response to the most positive event of the day girls were more likely to report savoring in response to positive events, suggesting a general tendency of female youths to allocate attention to emotionally salient stimuli in their daily lives.

\section{The relationship between positive and negative emotion regulation}

Few studies have investigated the relationship between emotion regulation in response to positive and negative emotions. In the current study, we explored these associations in daily life and found that more savoring was associated with more negative rumination and that expressing emotions related positive events was positively associated with expressing emotions related to negative events, and that positive and negative sharing were also positively associated. In contrast to the current findings, studies using trait measures have found that the ability to downregulate negative emotions and upregulate of positive emotions appears to be only modestly related (Nelis, Quoidbach, Hansenne, Mikolajczak, 2011). In one daily life study of rumination, only $10 \%$ of people were categorised as multivalence ruminators, based on reporting above average amounts of ruminating and savouring in response to daily events (Graf, Ramsey, Patrick, \& Gentzler, 2016). In addition, in a public speech task experiment, negative and positive rumination about the speech were only negligibly related (Abbot \& Rapee, 2004). Given the mixed findings, further research is necessary to determine if repetitive thought of any 
valence is indeed trait-like, as has been suggested (Roach, Salt, \& Segerstrom, 2010) or if savouring and rumination are orthogonal processes. Regarding emotion expression across valences, the current findings are in line with previous research suggesting that emotional expressiveness is associated with other relatively stable factors such as gender (Fischer \& LaFrance, 2015). Finally, sharing more across positive and negative events could reflect the availability of social support, and future studies may explore if availability of social support is related to sharing in daily life.

\section{Strengths and limitations}

The findings of the current study should also be interpreted within the context of its limitations. In the current study, the response scale for event intensity was short and did not relate to any specific emotions, but rather how pleasant to unpleasant the event was experienced as. A winder response scale will be useful in further studies. We also note that discrete emotions were not assessed in the current study, which limits conclusions about the universality of the findings across different positive and negative emotions. We therefore encourage future research on daily life emotion regulation to include discrete positive and negative emotions, in addition to contextual factors and mental health variables.

An important limitation of the current study is also that affect was not measured at the time the positive and negative events were taking place, but retrospectively at the end of each day of the ESM period (i.e., by asking participants to rate the intensity of the most positive and negative event of the day). Therefore, the measure of intensity in the current study could reflect the result of regulation, as opposed to its determinant. Our results on the negative relationship between reappraisal and intensity of negative stimuli do, however, align with those from lab experiments (Sheppes et al., 2011; Sheppes et al., 2014). Indeed, if the measure of intensity used in the current study represented the result of regulation, this would suggest that in response to negative events, strategies associated with higher negative intensity in the current study (i.e., 
social sharing, expression, situation modification, and rumination) are less effective than strategies associated with lower intensity (i.e., reappraisal and acceptance). However, in daily diary studies, sharing about negative events has been found to be effective (Brans, Koval, Verduyn, Lim, \& Kuppens, 2013). Moreover, both sharing and situation modification have been found to be more effective in daily life compared to reappraisal (Heiy \& Cheavens, 2014), suggesting that participants in the current study were reporting accurately on the intensity of events as opposed to the result of their emotion regulation. Yet, it is possible that intense emotions are more difficult to regulate and more persistent (Tull \& Aldoa, 2015), and the measure of intensity in the current study may therefore reflect both current emotions and emotions at the time of the event simultaneously. Finally, as the data set did not include moment-to-moment measures of emotion regulation and instead participants reported on their emotion regulation once a day for six days, we note that our ability to draw conclusions about how people generally regulate their emotions is limited.

Even with the limitations described above, this study has numerous strengths, including its ecological validity, the implementation of Open Science practices, and the large sample size. The assessment of emotion regulation in daily life is an emerging field and poses novel challenges. The strength of the evening questionnaire is that it allows participants to report on their emotion regulation at a longer time scale, while momentary questionnaires may not provide a long enough window for most of the consequent emotion regulation to take place across the day in response to a single event. However, in order to better tease apart emotions from emotion regulation, the development of more sophisticated designs and mobile applications is necessary. For instance, instead of asking participants to reflect on how much they think about an event or how often it reappears on their mind, we may rather calculate this information from data about thoughts that participants record throughout the day and provide 
participants with an end-of-the-day, user-friendly way to label which of their thoughts regarded the same events.

Another strength of our study is the use of Open Science practices; research questions, hypotheses, analysis plan, and code were (post)registered (Benning et al., 2019) on the Open Science Framework prior to data access. Open science practises are presently emerging in ESM research, but are not yet commonplace within the field (Kirtley, Lafit, Achterhof, Hiekkaranta, \& Myin-Germeys, 2020) and with the current study we hope to demonstrate some possibilities with registration with complex data structures, as well as a potential method of power analysis for pre-existing ESM data.

\section{Conclusion}

In the current study, we found that in youth, the intensity of both positive and negative events was associated with greater emotion regulation effort. The results also suggest that psychopathology and the regulation of negative emotions may not be directly related. Rather, it appears that increased intensity of daily negative events explains the previously reported relationships between psychopathology and many emotion regulation strategies. The only exception to this finding was rumination, as those with higher psychopathology ruminated more regardless of the intensity of negative events. These results emphasise the importance of including contextual factors such as intensity when relationships between psychopathology and emotion regulation are assessed. We also found strong evidence for polyregulation in response to both positive and negative events. Finally, the current study is among the first to explore the relationship between daily regulation of positive and negative emotions in youth and results suggests that general styles of emotion regulation may be present across positive and negative events. 


\section{References}

Abbott, M. J., \& Rapee, R. M. (2004). Post-event rumination and negative self-appraisal in social phobia before and after treatment. Journal of Abnormal Psychology, 113(1), 136. http://dx.doi.org/10.1037/0021-843X.113.1.136

Achterhof, R., Kirtley, O. J., Schneider, M., Hagemann, N., Hermans, K., Hiekkaranta, A. P., ... Myin-Germeys, I. (2020). General psychopathology and its social correlates in the daily lives of youth. PsyArXiv. https://doi.org/10.31234/osf.io/76xfs

Aldao, A. (2013). The future of emotion regulation research: Capturing context. Perspectives on Psychological Science, 8(2), 155-172. http://dx.doi.org/10.1177/1745691612459518

Aldao, A., Nolen-Hoeksema, S., \& Schweizer, S. (2010). Emotion-regulation strategies across psychopathology: A meta-analytic review. Clinical Psychology Review, 30(2), $217-$ 237. http://dx.doi.org/10.1016/j.cpr.2009.11.004

Ali, A., Ali, S., Khan, S. A., Khan, D. M., Abbas, K., Khalil, A., ... \& Khalil, U. (2019). Sample size issues in multilevel logistic regression models. PloS One, 14(11). http://dx.doi.org/10.1371/journal.pone.0225427

Arend, M. G., \& Schäfer, T. (2019). Statistical power in two-level models: A tutorial based on Monte Carlo simulation. Psychological Methods, 24(1), 1. http://dx.doi.org/10.1037/met0000195

Bates, D., Maechler, M., Bolker, B., Walker, S. (2015). Fitting Linear Mixed-Effects Models Using lme4. Journal of Statistical Software, 67(1). https://doi.org/10.18637/jss.v067.i01

Benning, S. D., Bachrach, R. L., Smith, E. A., Freeman, A. J., \& Wright, A. G. (2019). The registration continuum in clinical science: A guide toward transparent practices. Journal of Abnormal Psychology, 128(6), 528. http://dx.doi.org/10.1037/abn0000451

Berking, M., Wupperman, P., Reichardt, A., Pejic, T., Dippel, A., \& Znoj, H. (2008). Emotion-regulation skills as a treatment target in psychotherapy. Behaviour Research and Therapy, 46(11), 1230-1237. http://dx.doi.org/10.1016/j.brat.2008.08.005 
Blalock, D. V., Kashdan, T. B., \& Farmer, A. S. (2016). Trait and daily emotion regulation in social anxiety disorder. Cognitive Therapy and Research, 40(3), 416-425. https://doi.org/10.1007/s10608-015-9739-8

Bolger, N., Stadler, G., \& Laurenceau, J.-P. (2012). Power analysis for intensive longitudinal studies. In M. R. Mehl \& T. S. Conner (Eds.), Handbook of research methods for studying daily life (p. 285-301). The Guilford Press.

Brans, K., Koval, P., Verduyn, P., Lim, Y. L., \& Kuppens, P. (2013). The regulation of negative and positive affect in daily life. Emotion, 13(5), 926. http://dx.doi.org/10.1037/a0032400

Bryant, F. (2003). Savoring Beliefs Inventory (SBI): A scale for measuring beliefs about savouring. Journal of Mental Health, 12(2), 175-196. https://doi.org/10.1080/0963823031000103489

Carl, J. R., Soskin, D. P., Kerns, C., \& Barlow, D. H. (2013). Positive emotion regulation in emotional disorders: A theoretical review. Clinical Psychology Review, 33(3), 343360. http://dx.doi.org/10.1016/j.cpr.2013.01.003

Compas, B. E., Jaser, S. S., Bettis, A. H., Watson, K. H., Gruhn, M. A., Dunbar, J. P., ... \& Thigpen, J. C. (2017). Coping, emotion regulation, and psychopathology in childhood and adolescence: A meta-analysis and narrative review. Psychological Bulletin, 143(9), 939. http://dx.doi.org/10.1037/bul0000110

Csikszentmihalyi, M., \& Larson, R. (1987). The experience sampling method: Toward a systematic phenomenology. Journal of Nervous and Mental Disease, 175, 526-536.

Csikszentmihalyi, M., \& Larson, R. (1984). Being adolescent. New York: Basic Books.

Deng, X., Sang, B., \& Luan, Z. (2013). Up-and down-regulation of daily emotion: An experience sampling study of Chinese adolescents' regulatory tendency and effects. Psychological Reports, 113(2), 552-565. https://doi.org/10.2466/09.10.PR0.113x22z4

Derogatis, L. R. (1979). Symptom Checklist-90-Revised (SCL-90-R). Lyndhurst, NJ: NCS Pearson.

Derom, C., Thiery, E., Rutten, B. P. F., Peeters, H., Gielen, M., Bijnens, E., \& Weyers, V. S., (2019) The East Flanders Prospective Twin Survey (EFPTS): 55 Years Esmée Robert 
Twin Research and Human Genetics, 22(6), $454-459$.

http://dx.doi.org/10.1375/twin.9.6.733

Dixon-Gordon, K. L., Aldao, A., \& De Los Reyes, A. (2015). Emotion regulation in context: Examining the spontaneous use of strategies across emotional intensity and type of emotion. Personality and Individual Differences, 86, 271-276. http://dx.doi.org/10.1016/j.paid.2015.06.011

Fischer, A., \& LaFrance, M. (2015). What drives the smile and the tear: Why women are more emotionally expressive than men?. Emotion Review, 7(1), 22-29. http://dx.doi.org/10.1177/1754073914544406

Folkman, S., \& Lazarus, R. S. (1980). An analysis of coping in a middleaged community sample. Journal of Health and Social Behavior, 21, 219-239. https://doi.org/10.2307/2136617

Ford, B. Q., Gross, J. J., \& Gruber, J. (2019). Broadening Our Field of View: The Role of Emotion Polyregulation. Emotion Review, 11(3), 197-208. http://dx.doi.org/10.1177/1754073919850314

Fredrickson, B. L. (2001). The role of positive emotions in positive psychology: The broadenand-build theory of positive emotions. American Psychologist, 56(3), 218. http://dx.doi.org/10.1037/0003-066X.56.3.218

Fredrickson, B. L. (1998). What good are positive emotions?. Review of General Psychology, 2(3), 300-319. http://dx.doi.org/10.1037/1089-2680.2.3.300

Gable, S. L., Reis, H. T., Impett, E., \& Asher, E. R. (2004). What do you do when things go right? The intrapersonal and interpersonal benefits of sharing positive events. Journal of Personality and Social Psychology, 87, 228-245. http://dx.doi.org/10.1037/00223514.87.2.228.

Gable, S. L., \& Reis, H. T. (2010). Good news! Capitalizing on positive events in an interpersonal context. Advances in Experimental Social Psychology, 42, 195-257. http://dx.doi.org/10.1016/S0065- 2601(10)42004-3

Gomez-Baya, D., Mendoza, R., Gaspar, T., \& Gomes, P. (2018). Responses to positive affect, life satisfaction and self-esteem: A cross-lagged panel analysis during middle 
adolescence. Scandinavian Journal of Psychology, 59, 462-472. http://dx.doi.org/10.1111/sjop.12450

Graf, A. S., Ramsey, M. A., Patrick, J. H., \& Gentzler, A. L. (2016). Dark storm clouds and rays of sunshine: Profiles of negative and positive rumination about daily hassles and uplifts. Journal of Happiness Studies, 17(6), 2257-2276. http://dx.doi.org/10.1007/s10902-015-9693-x

Gross, J. J. (1998). The emerging field of emotion regulation: An integrative review. Review of General Psychology, 2(3), 271-299. https://doi.org/10.1037/1089-2680.2.3.271

Gross, J. J. (2015). Emotion regulation: Current status and future prospects. Psychological Inquiry, 26(1), 1-26. https://doi.org/10.1080/1047840X.2014.940781

Gruber, J., Kogan, A., Mennin, D., \& Murray, G. (2013). Real-world emotion? An experience-sampling approach to emotion experience and regulation in bipolar I disorder. Journal of Abnormal Psychology, 122(4), 971. http://dx.doi.org/10.1037/a0034425

Heiy, J. E., \& Cheavens, J. S. (2014). Back to basics: A naturalistic assessment of the experience and regulation of emotion. Emotion, 14, 878- 891. http://dx.doi.org/10.1037/a0037231

Hershenberg, R., Davila, J., \& Leong, S. H. (2014). Depressive symptoms in women and the preference and emotional benefits of discussing positive life events. Journal of Social and Clinical Psychology, 33(9), 767-788. https://doi.org/10.1521jscp2014339767

Hox, J. (2010). Multilevel Analysis: Techniques and Applications. New York: Routledge.

Jose, P. E., \& Brown, I. (2008). When does the gender difference in rumination begin? Gender and age differences in the use of rumination by adolescents. Journal of Youth and Adolescence, 37(2), 180-192. http://dx.doi.org/10.1007/s10964-006-9166-y

Kelley, J., Evans, M. D. R., Lowman, J., \& Lykes, V. (2017). Group-mean-centering independent variables in multi-level models is dangerous. Quality \& Quantity, 51(1), 261-283. http://dx.doi.org/10.1007/s11135-015-0304-Z

Kirtley, O. J., Lafit, G., Achterhof, R., Hiekkaranta, A. P., \& Myin-Germeys, I. (2020). Making the black box transparent: A pre-registration template for studies using 
Experience Sampling Methods (ESM). Advances in Methods and Practices in Psychological Science (accepted). http://dx.doi.org/10.31234/osf.io/seyq7

Kirtley, O. J., Hiekkaranta, A. P., Kunkels, Y. K., Verhoeven, D., Van Nierop, M., \& MyinGermeys, I. (2019). The Experience Sampling Method (ESM) Item Repository. OSF. https://doi .org/10.17605/OSF.IO/KG376

Kuznetsova, A, Brockhoff, P.B., Christensen, R. H. B. (2017). lmerTest Package: Tests in Linear Mixed Effects Models. Journal of Statistical Software, 82(13), 1-26. http://dx.doi.org/10.18637/jss.v082.i13

Larson, R., \& Richards, M. H. (1994). Divergent realities: The emotional lives of mothers, fathers, and adolescents. New York: Basic Books.

Lennarz, H. K., Hollenstein, T., Lichtwarck-Aschoff, A., Kuntsche, E., \& Granic, I. (2019). Emotion regulation in action: Use, selection, and success of emotion regulation in adolescents' daily lives. International Journal of Behavioral Development, 43(1), 111. http://dx.doi.org/10.1177/0165025418755540

Li, Y. I., Starr, L. R., \& Hershenberg, R. (2017). Responses to positive affect in daily life: Positive rumination and dampening moderate the association between daily events and depressive symptoms. Journal of Psychopathology and Behavioral Assessment, 39(3), 412-425. http://dx.doi.org/10.1007/s10862-017-9593-y

Ma, T. W., Bryant, F. B., \& Hou, W. K. (2020). Associations of trait positive emotion regulation with everyday emotions: An experience sampling approach. International Journal of Psychology. http://dx.doi.org/10.1002/ijop.12650

McMahon, T. P., \& Naragon-Gainey, K. (2019). The multilevel structure of daily emotionregulation strategy use: An examination of within- and between-person associations in naturalistic settings. Clinical Psychological Science, 7, 321-339. http://dx.doi.org/10.1177/2167702618807408

Mestdagh, M., \& Dejonckheere, E. (2021). Ambulatory assessment in psychopathology research: Current achievements and future ambitions. Current Opinion in Psychology, 21(1), 1-8. https://doi.org/10.1016/j.copsyc.2021.01.004

Myin-Germeys, I., Kasanova, Z., Vaessen, T., Vachon, H., Kirtley, O., Viechtbauer, W., \& Reininghaus, U. (2018). Experience sampling methodology in mental health research: 
new insights and technical developments. World Psychiatry, 17(2), 123-132. http://dx.doi.org/10.1002/wps.20513

Myin-Germeys, I., Peeters, F. P. M. L., Havermans, R., Nicolson, N. A., DeVries, M. W., Delespaul, P. A. E. G., \& Van Os, J. (2003). Emotional reactivity to daily life stress in psychosis and affective disorder: an experience sampling study. Acta Psychiatrica Scandinavica, 107(2), 124-131. http://dx.doi.org/10.1034/j.1600-0447.2003.02025.x

Nelis, D., Quoidbach, J., Hansenne, M., \& Mikolajczak, M. (2011). Measuring individual differences in emotion regulation: The Emotion Regulation Profile-Revised (ERP-R). Psychologica Belgica, 51(1), 49-91. http://dx.doi.org/10.5334/pb-51-1-49

Panaite, V., Devendorf, A. R., Kashdan, T. B., \& Rottenberg, J. (2021). Daily Life Positive Events Predict Well-Being Among Depressed Adults 10 Years Later. Clinical Psychological Science, 9(2), 222-235. https://doi.org/10.1177/2167702620956967

Peters, B. J. , Reis, H. T. , \& Gable, S. L. (2018). Making the good even better: A review and theoretical model of interpersonal capitalization. Social and Personality Psychology Compass,12(7), e12407. https://doi.org/10.1111/spc3.12407

Pries, L. K., Guloksuz, S., Menne-Lothmann, C., Decoster, J., van Winkel, R., Collip, D., ... \& Jacobs, N. (2017). White noise speech illusion and psychosis expression: An experimental investigation of psychosis liability. PloS One, 12(8). http://dx.doi.org/10.1371/journal.pone.0183695

Quoidbach, J., Berry, E. V., Hansenne, M., \& Mikolajczak, M. (2010). Positive emotion regulation and well-being: Comparing the impact of eight savoring and dampening strategies. Personality and Individual Differences, 49, 368-373. http://dx.doi.org/10.1016/j.paid.2010.03.048

R Core Team (2019). R: A language and environment for statistical computing. R Foundation for Statistical Computing, Vienna, Austria. URL https://www.R-project.org/.

Rimé, B., Finkenauer, C., Luminet, O., Zech, E., \& Philippot, P. (1998). Social sharing of emotion: New evidence and new questions. European Review of Social Psychology, 9(1), 145-189. https://doi.org/10.1080/14792779843000072 
Roach, A. R., Salt, C. E., \& Segerstrom, S. C. (2010). Generalizability of repetitive thought: Examining stability in thought content and process. Cognitive Therapy and Research, 34(2), 144-158. http://dx.doi.org/10.1007/s10608-009-9232-3

RStudio Team (2015). RStudio: Integrated Development for R. RStudio, Inc., Boston, MA URL http://www.rstudio.com/

Sawyer, S. M., Azzopardi, P. S., Wickremarathne, D., \& Patton, G. C. (2018). The age of adolescence. The Lancet Child \& Adolescent Health, 2(3), 223-228. http://dx.doi.org/10.1016/S2352-4642(18)30022-1

Sheppes, G., Scheibe, S., Suri, G., \& Gross, J. J. (2011). Emotion regulation choice. Psychological Science, 22, 1391-1396. doi:10.1177/0956797611418350

Sheppes, G., Scheibe, S., Suri, G., Radu, P., Blechert, J., \& Gross, J. J. (2014). Emotion regulation choice: a conceptual framework and supporting evidence. Journal of Experimental Psychology: General, 143(1), 163. http://dx.doi.org/10.1037/a0030831

Silk, J. S., Steinberg, L., \& Morris, A. S. (2003). Adolescents' emotion regulation in daily life: Links to depressive symptoms and problem behavior. Child Development, 74(6), 1869-1880. http://dx.doi.org/10.1046/j.1467-8624.2003.00643.x

Sloan, E., Hall, K., Youssef, G. J., Moulding, R., Mildred, H., \& Staiger, P. K. (2019). Profiles of emotion regulation in young people accessing youth mental health and drug treatment. Cognitive Therapy and Research, 43(4), 769-780. http://dx.doi.org/10.1007/s10608-019-10003-4

Stochl, J., Khandaker, G. M., Lewis, G., Perez, J., Goodyer, I. M., Zammit, S., ... \& Jones, P. B. (2015). Mood, anxiety and psychotic phenomena measure a common psychopathological factor. Psychological Medicine, 45(7), 1483-1493. http://dx.doi.org/10.1017/S003329171400261X

Tan, P. Z., Forbes, E. E., Dahl, R. E., Ryan, N. D., Siegle, G. J., Ladouceur, C. D., \& Silk, J. S. (2012). Emotional reactivity and regulation in anxious and nonanxious youth: A cell-phone ecological momentary assessment study. Journal of Child Psychology and Psychiatry, 53(2), 197-206. http://dx.doi.org/10.1111/j.1469-7610.2011.02469.x

Taylor, S. E., Klein, L. C., Lewis, B. P., Gruenewald, T. L., Gurung, R. A., \& Updegraff, J. A. (2000). Biobehavioral responses to stress in females: tend-and-befriend, not fight-or- 
flight. Psychological Review, 107(3), 411. http://dx.doi.org/10.1037/0033-

295X.107.3.411

Tull, M. T., \& Aldao, A. (2015). Editorial overview: New directions in the science of emotion regulation. Current Opinion in Psychology, 3, iv-x. http://dx.doi.org/10.1016/j.copsyc.2015.03.009

Vaessen, T., van Nierop, M., Decoster, J., Delespaul, P., Derom, C., De Hert, M., ... \& van Os, J. (2017). Is sensitivity to daily stress predictive of onset or persistence of psychopathology?. European Psychiatry, 45, 167-173. http://dx.doi.org/10.1016/j.eurpsy.2017.07.002

Verma, S., \& Larson, R. (1999). Are Adolescents More Emotional? A Study of the Daily Emotions of Middle Class Indian Adolescents1. Psychology and Developing Societies, 11(2), 179-194. http://dx.doi.org/10.1177/097133369901100204

Visser, K. F., Esfahlani, F. Z., Sayama, H., \& Strauss, G. P. (2018). An ecological momentary assessment evaluation of emotion regulation abnormalities in schizophrenia. Psychological Medicine, 48(14), 2337-2345. http://dx.doi.org/10.1017/S0033291717003865

Wright, A. G., \& Zimmermann, J. (2019). Applied ambulatory assessment: Integrating idiographic and nomothetic principles of measurement. Psychological Assessment, 31(12), 1467. http://dx.doi.org/10.1037/pas0000685 


\section{Tables}

Table 1. Descriptive statistics. $N=713$.

\begin{tabular}{|c|c|c|c|c|c|}
\hline & Variable & $\begin{array}{l}\text { Mean } \\
(\mathrm{SD})\end{array}$ & Median & Range & $\begin{array}{l}\% \text { of } \\
\text { use }\end{array}$ \\
\hline \multirow[t]{2}{*}{ Demographics } & Age & $17.6(2.3)$ & 16.1 & $14.2-24.6$ & \\
\hline & Gender (\%females) & 57.8 & - & - & \\
\hline \multirow[t]{2}{*}{ Psychopathology } & Depression, Anxiety, & 18.6 & 12.0 & $0.0-142.0$ & \\
\hline & $\begin{array}{l}\text { Psychoticism, Paranoid } \\
\text { ideation (sum) }\end{array}$ & $(19.2)$ & & & \\
\hline \multirow{11}{*}{$\begin{array}{l}\text { Daily most } \\
\text { negative event }\end{array}$} & Acceptance & $4.4(1.8)$ & 5.0 & $1.0-7.0$ & $88.3 \%$ \\
\hline & Reappraisal & $4.5(1.8)$ & 5.0 & $1.0-7.0$ & $88.1 \%$ \\
\hline & Avoidance & $4.2(1.9)$ & 4.0 & $1.0-7.0$ & $86.1 \%$ \\
\hline & Situation modification & $3.3(2.0)$ & 3.0 & $1.0-7.0$ & $70.0 \%$ \\
\hline & Rumination & $3.1(2.0)$ & 3.0 & $1.0-7.0$ & $66.7 \%$ \\
\hline & Expression & $3.1(2.0)$ & 3.0 & $1.0-7.0$ & $65.8 \%$ \\
\hline & Sharing (\%yes) & 51.6 & - & - & $51.6 \%$ \\
\hline & Total emotion & $22.4(5.1)$ & 23.0 & $6.0-36.0$ & \\
\hline & regulation effort & & & & \\
\hline & Number of strategies & $5.2(1.6)$ & 5.0 & $0.0-7.0$ & \\
\hline & Event intensity & -1.6 & -1.0 & $-3.0-0.0$ & \\
\hline \multirow{5}{*}{$\begin{array}{l}\text { Daily most } \\
\text { positive event }\end{array}$} & Savoring & $4.4(1.9)$ & 5.0 & $1.0-7.0$ & $86.9 \%$ \\
\hline & Expression & $3.9(2.0)$ & 4.0 & $1.0-7.0$ & $76.8 \%$ \\
\hline & Sharing (\%yes) & 60.8 & - & - & $60.8 \%$ \\
\hline & Number of strategies & $2.3(0.9)$ & 2.0 & $0.0-3.0$ & \\
\hline & Event intensity & $2.3(0.9)$ & 3.0 & $0.0-3.0$ & \\
\hline
\end{tabular}


Table 2. Negative events. Results of mixed multilevel analyses. Effect size $\beta$ per independent variable and per emotion regulation outcome.

\begin{tabular}{|c|c|c|c|c|c|c|}
\hline Outcome & & Psychopathology & Intensity $^{\mathrm{a}}$ & $\begin{array}{c}\text { Psychopathology } \\
\text { x Intensity }\end{array}$ & Age & Gender $^{b}$ \\
\hline \multirow[t]{2}{*}{ Total effort } & $\beta(S E)$ & $0.11(0.50)$ & $\mathbf{- 0 . 8 0}(0.13)^{* * *}$ & $-0.22(0.21)$ & $0.13(0.06)$ & $1.15(0.27)^{* * *}$ \\
\hline & p-value & 0.825 & $<.001$ & 0.283 & 0.012 & $<.001$ \\
\hline \multirow[t]{2}{*}{ Number of strategies } & $\beta(S E)$ & $0.18(0.16)$ & $\mathbf{- 0 . 2 8}(0.04)^{* * *}$ & $-0.07(0.06)$ & $\mathbf{0 . 0 7}(0.02)^{* * *}$ & $\mathbf{0 . 3 7}(0.08) * * *$ \\
\hline & p-value & 0.282 & $<.001$ & 0.262 & $<.001$ & $<.001$ \\
\hline \multirow[t]{2}{*}{ Rumination } & $\beta(S E)$ & $\mathbf{0 . 6 7}(0.15)^{* * *}$ & $\mathbf{- 0 . 7 2}(0.05)^{* * *}$ & $0.01(0.07)$ & $0.03(0.02)$ & $\mathbf{0 . 3 3}(0.09)^{* * *}$ \\
\hline & p-value & $<.001$ & $<.001$ & 0.883 & 0.070 & $<.001$ \\
\hline \multirow[t]{2}{*}{ Situation modification } & $\beta(S E)$ & $0.16(0.17)$ & $\mathbf{- 0 . 2 4}(0.05)^{* * *}$ & $-0.02(0.08)$ & $0.02(0.02)$ & $0.13(0.10)$ \\
\hline & $\mathrm{p}$-value & 0.346 & $<.001$ & 0.882 & 0.313 & 0.191 \\
\hline \multirow[t]{2}{*}{ Avoidance } & $\beta(S E)$ & $0.04(0.18)$ & $0.07(0.05)$ & $-0.02(0.08)$ & $-0.02(0.02)$ & $0.03(0.09)$ \\
\hline & p-value & 0.847 & 0.158 & 0.756 & 0.398 & 0.701 \\
\hline \multirow[t]{2}{*}{ Acceptance } & $\beta(S E)$ & $-0.29(0.18)$ & $\mathbf{0 . 2 5}(0.05)^{* * *}$ & $-0.13(0.08)$ & $-0.03(0.02)$ & $\mathbf{- 0 . 3 6}(0.09) * * *$ \\
\hline & $\mathrm{p}$-value & 0.113 & $<.001$ & 0.102 & 0.135 & $<.001$ \\
\hline \multirow[t]{2}{*}{ Expression } & $\beta(S E)$ & $-0.18(0.17)$ & $\mathbf{- 0 . 3 4}(0.05)^{* * *}$ & $-0.10(0.07)$ & $0.04(0.02)$ & $\mathbf{0 . 7 7}(0.10)^{* * *}$ \\
\hline & p-value & 0.277 & $<.001$ & 0.216 & 0.060 & $<.001$ \\
\hline \multirow[t]{2}{*}{ Reappraisal } & $\beta(S E)$ & $-0.24(0.18)$ & $\mathbf{0 . 1 6}(0.05)^{* *}$ & $0.04(0.08)$ & $\mathbf{0 . 0 7}(0.02)^{* * *}$ & $0.17(0.09)$ \\
\hline & $\mathrm{p}$-value & 0.197 & 0.002 & 0.588 & $<.001$ & 0.071 \\
\hline \multirow[t]{2}{*}{ Sharing } & $\beta(S E)$ & $-0.55(0.23)^{*}$ & $\mathbf{- 0 . 4 4}(0.06)^{* * *}$ & $-0.04(0.10)$ & $0.01(0.02)$ & $\mathbf{0 . 4 5}(0.11)^{* * *}$ \\
\hline & $\mathrm{p}$-value & 0.015 & $<.001$ & 0.658 & 0.604 & $<.001$ \\
\hline
\end{tabular}

Note. $* \mathrm{p}<0.05, \mathrm{p}<0.01 * *, \mathrm{p}<0.001 * * *$. 
The scoring of this variable was: $-3=$ very unpleasant, $0=$ neutral.

${ }^{\mathrm{b}}$ Betas represent the effect of being female.

Table 3. Positive events. Results of mixed multilevel analyses. Effect size $\beta$ per independent variable and per emotion regulation outcome.

\begin{tabular}{|c|c|c|c|c|c|c|}
\hline Outcome & & Psychopathology & Intensity $^{\mathrm{a}}$ & $\begin{array}{l}\text { Psychopathology } \\
\text { x Intensity }\end{array}$ & Age & Gender $^{\mathrm{b}}$ \\
\hline \multirow[t]{2}{*}{ Number of strategies } & $\beta(S E)$ & $0.02(0.11)$ & $\mathbf{0 . 2 0}(0.03)^{* * *}$ & $-0.02(0.04)$ & $\mathbf{0 . 0 3}(0.00)^{* *}$ & $\mathbf{0 . 2 5}(0.05)^{* * *}$ \\
\hline & p-value & 0.827 & $<.001$ & 0.633 & 0.002 & $<.001$ \\
\hline \multirow[t]{2}{*}{ Savoring } & $\beta(S E)$ & $0.10(0.20)$ & $\mathbf{0 . 6 6}(0.06)^{* * *}$ & $0.10(0.08)$ & $\mathbf{0 . 0 6}(0.02)^{* *}$ & $0.26(0.09) * *$ \\
\hline & p-value & 0.618 & $<.001$ & 0.205 & 0.002 & 0.003 \\
\hline \multirow[t]{2}{*}{ Expression } & $\beta(S E)$ & $0.03(0.21)$ & $\mathbf{0 . 4 4}(0.06)^{* * *}$ & $0.00(0.00)$ & $\mathbf{0 . 0 6}(0.02)^{*}$ & $\mathbf{0 . 6 3}(0.11)^{* * *}$ \\
\hline & $\mathrm{p}$-value & 0.890 & $<.001$ & 0.950 & 0.015 & $<.001$ \\
\hline \multirow[t]{2}{*}{ Sharing $^{c}$} & $\beta(S E)$ & $0.11(0.28)$ & $\mathbf{0 . 6 4}(0.08)^{* * *}$ & $-0.18(0.11)$ & $-0.02(0.03)$ & $0.54(0.13) * * *$ \\
\hline & p-value & 0.672 & $<.001$ & 0.10 & 0.563 & $<.001$ \\
\hline
\end{tabular}

Note. $* \mathrm{p}<0.05, \mathrm{p}<0.01 * *, \mathrm{p}<0.001 * * *$.

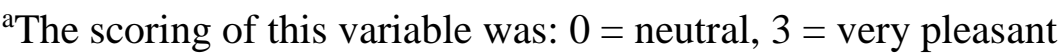

${ }^{b}$ Betas represent the effect of being female. 
Table 4. Results of mixed multilevel analyses. The effect size $\beta$ of psychopathology and covariates on the experience of intensity of daily most negative and positive event and the associations between positive and negative emotion regulation.

\begin{tabular}{|c|c|c|c|c|c|c|c|c|}
\hline Outcome & & & Age & Gender $^{\mathrm{a}}$ & Psychopathology & $\begin{array}{c}\text { Rumination } \\
\text { negative } \\
\text { event }\end{array}$ & $\begin{array}{c}\text { Expression } \\
\text { negative } \\
\text { event }\end{array}$ & $\begin{array}{c}\text { Sharing } \\
\text { negative } \\
\text { event }\end{array}$ \\
\hline & \multirow[t]{2}{*}{ Intensity negative event } & $\beta(S E)$ & $0.02(0.02)$ & $0.02(0.05)$ & $\mathbf{- 0 . 3 6}(0.06)^{* * *}$ & & & \\
\hline & & p-value & 0.170 & 0.695 & $<.001$ & & & \\
\hline & \multirow[t]{2}{*}{ Intensity positive event } & $\beta(S E)$ & $0.00(0.01)$ & $\mathbf{0 . 1 6}(0.05)^{* *}$ & $-0.05(0.05)$ & & & \\
\hline & & $\mathrm{p}$-value & 0.674 & $<.001$ & 0.267 & & & \\
\hline & \multirow[t]{2}{*}{ Savoring positive event } & $\beta(S E)$ & $\mathbf{0 . 0 5}(0.02)^{* *}$ & $\mathbf{0 . 3 3}(0.09)^{* *}$ & & $\mathbf{0 . 0 8}(0.02)^{* *}$ & & \\
\hline & & $\mathrm{p}$-value & 0.008 & $<.001$ & & $<.001$ & & \\
\hline & \multirow[t]{2}{*}{ Expression positive event } & $\beta(S E)$ & $\mathbf{0 . 0 5}(0.02)^{*}$ & $\mathbf{0 . 4 8}(0.10)^{* * *}$ & & & $\mathbf{0 . 2 0}(0.02)^{* *}$ & \\
\hline & & $\mathrm{p}$-value & 0.013 & $<.001$ & & & $<.001$ & \\
\hline & \multirow[t]{2}{*}{ Sharing positive event } & $\beta(S E)$ & $-0.03(0.06)$ & $0.49(0.12)^{* * *}$ & & & & $\begin{array}{l}\mathbf{0 . 5 7} \\
(0.10) * * *\end{array}$ \\
\hline & & p-value & 0.603 & $<.001$ & & & & $<.001$ \\
\hline
\end{tabular}

Note. $* \mathrm{p}<0.05, \mathrm{p}<0.01 * *, \mathrm{p}<0.001 * * *$.

${ }^{a}$ Betas represent the effect of being female. 